\title{
Predictive factor and antihypertensive usage of tyrosine kinase inhibitor-induced hypertension in kidney cancer patients
}

\author{
KOUJI IZUMI $^{1}$, SHINGO ITAI ${ }^{2}$, YOSHIKO TAKAHASHI ${ }^{2}$, AERKEN MAOLAKE $^{1}$ and MIKIO NAMIKI ${ }^{1}$ \\ Departments of ${ }^{1}$ Integrative Cancer Therapy and Urology and ${ }^{2}$ Medicinal Informatics, \\ Kanazawa University Graduate School of Medical Science, Kanazawa, Ishikawa 920-8641, Japan
}

Received September 20, 2013; Accepted March 4, 2014

DOI: $10.3892 / \mathrm{ol} .2014 .2060$

\begin{abstract}
Hypertension (HT) is the common adverse event associated with vascular endothelial growth factor receptor-tyrosine kinase inhibitors (VEGFR-TKI). The present study was performed to identify the predictive factors of TKI-induced HT and to determine the classes of antihypertensive agents (AHTA) that demonstrate optimal efficacy against this type of HT. The charts of 50 cases of patients that had received VEGFR-TKI treatment were retrospectively examined. The association between patient background and TKI-induced HT, and the effect of administering AHTA were analyzed. High systolic blood pressure at baseline was identified to be a predictive factor for HT. In addition, there was no difference observed between calcium channel blockers (CCBs) and angiotensin receptor II blockers (ARBs) as first-line AHTA for the control of HT. The findings of the present study may aid with predicting the onset of TKI-induced HT, as well as for its management via the primary use of either CCBs or ARBs.
\end{abstract}

\section{Introduction}

It had been indicated that antitumor agents do not have a beneficial effect on patient survival in cases of kidney cancer. Only cytokine therapies, including interferon- $\alpha$ and interleukin-2, have been used for patients with metastatic (or surgically unresectable) kidney cancer (MKC). However, these agents demonstrate insufficient efficacy (1-3). Subsequent to the phase III trial investigating the effects of sorafenib on MKC, the vascular endothelial growth factor (VEGF) signaling pathway inhibitors have emerged as leading treatments for MKC (4-8). Three VEGF receptor-tyrosine kinase inhibitors (VEGFR-TKI), sorafenib, sunitinib and axitinib,

Correspondence to: Dr Kouji Izumi, Department of Integrative Cancer Therapy and Urology, Kanazawa University Graduate School of Medical Science, 13-1 Takara-machi, Kanazawa, Ishikawa 920-8641, Japan

E-mail: azuizu2003@yahoo.co.jp

Key words: hypertension, kidney cancer, tyrosine kinase inhibitor are available for patients with MKC in Japan, as of 2012. The affinity and selectivity of VEGFR-TKI for VEGFR are varied, and accordingly the incidence and severity of adverse events (AE) also differ (5-7). Hypertension (HT) is the most common AE associated with VEGFR-TKI therapy and it occasionally becomes a critical factor for the discontinuation of the treatment (5-8). By contrast, the onset of HT following the initiation of VEGFR-TKI treatment has been reported as a possible biomarker of a good response to VEGFR-TKI (9). Therefore, the control of HT is extremely significant for the continued use of VEGFR-TKI and to achieve the optimal outcome in MKC treatment. The present study was performed to identify the predictive factors of VEGFR-TKI-induced HT, and to determine the classes of antihypertensive agents (AHTAs) that demonstrate the optimum efficacy against secondary HT.

\section{Patients and methods}

Study population. All studies were performed retrospectively in Kanazawa University (Kanazawa, Japan) using the charts of patients who were hospitalized at the Department of Urology. Patients with MKC who underwent VEGFR-TKI (sorafenib, sunitinib and axitinib) therapy were analyzed. The AHTAs that were administered were categorized according to their mechanisms of action. The study was in accordance with the Declaration of Helsinki Guidelines.

Definition of HT. HT was defined as systolic blood pressure (BP) of $>140 \mathrm{mmHg}$, corresponding to Grade 2 of the National Cancer Institute-Common Terminology Criteria for Adverse Events version 4.0 (10). The policy of the Department of Integrative Cancer Therapy and Urology, Kanazawa University Graduate School of Medical Science (Kanazawa, Japan) for commencing AHTA administration was also the same as the definition of HT. The BP of all cases was reviewed prior to VEGFR-TKI administration (baseline), between the onset of de novo HT and commencing AHTA administration, and on HT improvement following AHTA administration. The average BP levels at identical times on three consecutive days were calculated and used for analyses; however, single BP measurements were also used if the patient was discharged and became an outpatient.

Statistical analysis. Statistical analyses were performed using commercially available software (Prism; GraphPad Software, 
Table I. Patient demographics.

\begin{tabular}{|c|c|}
\hline Demographic & Value \\
\hline Number & 50 \\
\hline Median age, year & $65(26-85)$ \\
\hline \multicolumn{2}{|l|}{ Gender } \\
\hline Male & 43 \\
\hline Female & 7 \\
\hline \multicolumn{2}{|l|}{ Prior nephrectomy } \\
\hline Yes & 30 \\
\hline No & 20 \\
\hline \multicolumn{2}{|l|}{ TKI } \\
\hline Sorafenib & 18 \\
\hline Sunitinib & 27 \\
\hline Axitinib & 5 \\
\hline Median TKI administration days & $102(7-1117)$ \\
\hline \multicolumn{2}{|l|}{ Median initial BP } \\
\hline Systolic & $116(96-157)$ \\
\hline Diastolic & $72(57-90)$ \\
\hline \multicolumn{2}{|l|}{ Number of prior AHTA } \\
\hline 0 & 28 \\
\hline 1 & 13 \\
\hline 2 & 9 \\
\hline \multicolumn{2}{|l|}{ Prior AHTA } \\
\hline $\mathrm{CCB}$ & 17 \\
\hline ARB & $9^{\mathrm{a}}$ \\
\hline ACEI & 1 \\
\hline Others & 4 \\
\hline \multicolumn{2}{|l|}{ TKI-induced HT } \\
\hline Yes & 20 \\
\hline No & 30 \\
\hline
\end{tabular}

${ }^{\mathrm{a}}$ One mixture of ARB and diuretic was included. Values in parentheses indicate the range. TKI, tyrosine kinase inhibitor; BP, blood pressure; AHTA, antihypertensive agents; $\mathrm{CCB}$, calcium channel blocker; ARB, angiotensin receptor II blocker; ACEI, angiotensin converting enzyme inhibitors; HT, hypertension.

Inc., San Diego, CA, USA). Comparisons between two groups were performed by unpaired two-sided t-test, Fisher's exact test and $\chi^{2}$ test to identify trends. The probability of administrating AHTA was estimated using the Kaplan-Meier method. In all analyses, $\mathrm{P}<0.05$ was considered to indicate a statistically significant difference.

\section{Results}

Patient characteristics. In total, 50 VEGFR-TKI administration events from 41 patients were analyzed and the patient demographic data are shown in Table I. The number of cases of sorafenib, sunitinib and axitinib administration were 18 , 27 and 5, respectively. A total of 22 patients had pre-existing HT, and one or two AHTA had previously been prescribed. The probability of AHTA administration is shown in Fig. 1A.
Table II. Comparison of the backgrounds between HT and non-HT patients.

\begin{tabular}{|c|c|c|c|}
\hline Background & Non-HT & HT & P-value \\
\hline Number & 30 & 20 & \\
\hline Median age, year & $65(26-80)$ & $66(47-85)$ & 0.5992 \\
\hline \multicolumn{4}{|l|}{ Gender } \\
\hline Male & 26 & 17 & 1.0000 \\
\hline Female & 4 & 3 & \\
\hline \multicolumn{4}{|l|}{ Prior nephrectomy } \\
\hline Yes & 17 & 13 & 0.7688 \\
\hline No & 13 & 7 & \\
\hline \multicolumn{4}{|l|}{ TKI } \\
\hline Sorafenib & 11 & 7 & 0.9923 \\
\hline Sunitinib & 16 & 11 & \\
\hline Axitinib & 3 & 2 & \\
\hline $\begin{array}{l}\text { Median TKI } \\
\text { administration days }\end{array}$ & $69(5-1047)$ & $188(21-1117)$ & 0.1895 \\
\hline \multicolumn{4}{|l|}{ Median initial BP } \\
\hline Systolic & $114(96-133)$ & $122(104-157)$ & 0.0104 \\
\hline Diastolic & $70(58-83)$ & $74(57-90)$ & 0.2555 \\
\hline \multicolumn{4}{|c|}{ Number of prior AHTA } \\
\hline 0 & 15 & 13 & 0.3486 \\
\hline 1 & 10 & 3 & \\
\hline 2 & 5 & 4 & \\
\hline \multicolumn{4}{|l|}{ Administered AHTA } \\
\hline $\mathrm{CCB}$ & 13 & 4 & 0.3127 \\
\hline $\mathrm{ARB}$ & $5^{\mathrm{a}}$ & 4 & \\
\hline ACEI & 0 & 1 & \\
\hline Others & 2 & 2 & \\
\hline
\end{tabular}

${ }^{a}$ One mixture of ARB and diuretic was included. Values in parentheses indicate the range. HT, hypertension; TKI, tyrosine kinase inhibitor; $\mathrm{BP}$, blood pressure; AHTA, antihypertensive agents; CCB, calcium channel blocker; ARB, angiotensin receptor II blocker; ACEI, angiotensin converting enzyme inhibitors.

Predictive factor of VEGFR-TKI-induced HT. Of the 50 cases, 20 had HT subsequent to VEGFR-TKI administration, and their backgrounds were compared with the 30 non-HT cases (Table II). The median systolic BP at baseline was significantly higher in $20 \mathrm{HT}$ cases $(\mathrm{P}=0.0104)$, and the distributions of systolic BP in the non-HT and HT groups are shown in Fig. 1B. In total, 2 cases exhibited Grade 2 HT at baseline and commenced AHTA following the deterioration of HT to Grade 3 (systolic BP, $>160 \mathrm{mmHg}$ ). The distributions of BP at baseline and prior to AHTA administration in the HT group are also shown in Fig. 1C.

Administration of AHTA. The variations in efficacy, between AHTA administration in 13 cases of de novo HT and no AHTA administration prior to initiation of VEGFR-TKI therapy, were analyzed. The first-line AHTA treatment was either calcium channel blockers (CCBs) or angiotensin 
A

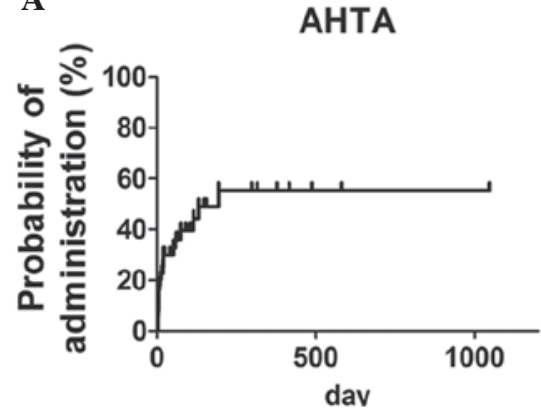

B

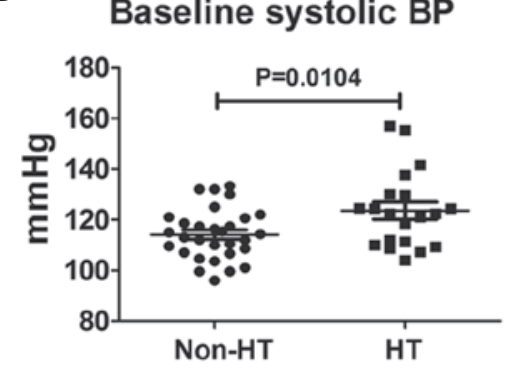

C

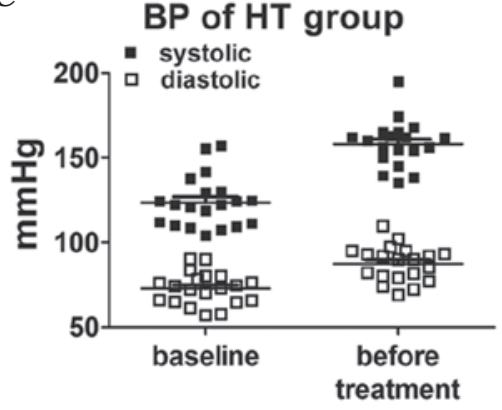

Figure 1. (A) Probability of administrating AHTA is shown using the Kaplan-Meier method. (B) Average systolic BP at baseline in non-HT (n=30) and HT $(n=20)$ groups. (C) Average systolic and diastolic BP at baseline and before AHTA administration in the HT group. AHTA, antihypertensive agents; BP, blood pressure; HT, hypertension.

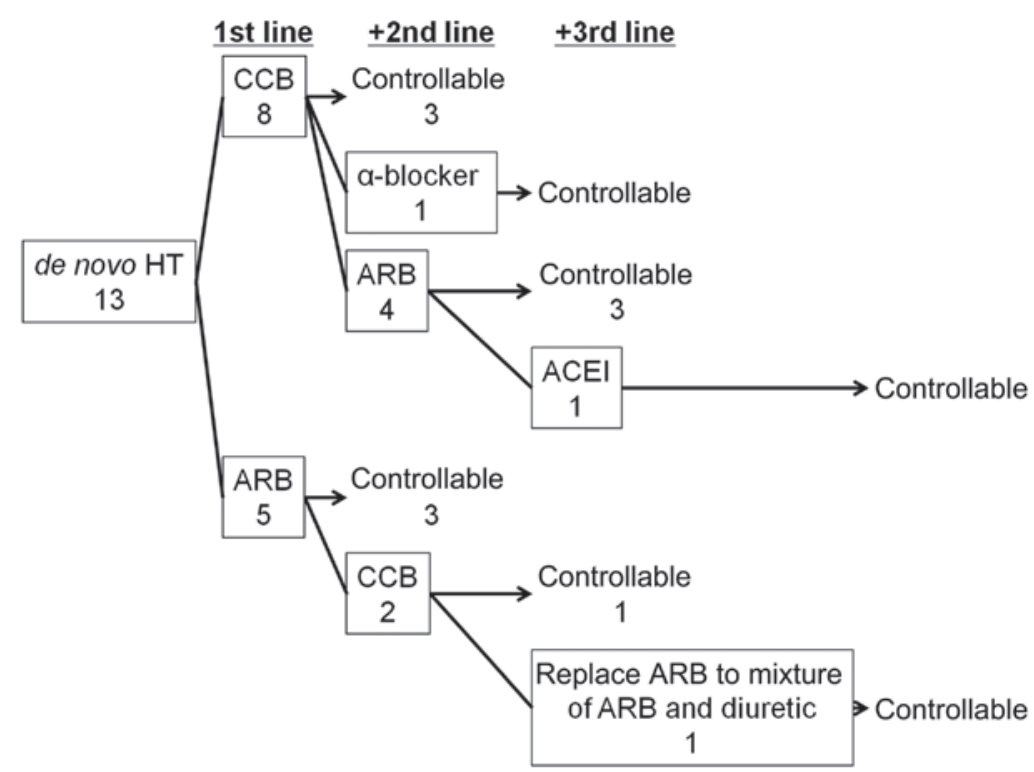

Figure 2. AHTA administered for EGFR-TKI-induced de novo HT are shown. CCB or ARB was administered for de novo HT as a first-line therapy, and second- and third-line AHTA were added if necessary. No significant difference was identified between the control rate of CCB and ARB as first-line treatments ( $\mathrm{P}=0.5921)$. AHTA, antihypertensive agents; EGFR-TKI, epidermal growth factor receptor-tyrosine kinase inhibitor; HT, hypertension; CCB, calcium channel blocker; ARB, angiotensin receptor II blocker; ACEI, angiotensin-converting enzyme inhibitor.

receptor II blockers (ARBs). There was no significant difference identified between the control rate of $\mathrm{CCB}$ and $\mathrm{ARB}$ as first-line treatments $(3 / 8$ for $\mathrm{CCB}$ treatment and $3 / 5$ for $\mathrm{ARB}$, $\mathrm{P}=0.5921$; Fig. 2).

\section{Discussion}

It is important to identify the predictive factors for key AE that are associated with VEGF-TKI to prevent treatment discontinuation, as well as to predict the population that may show a good response to these agents. Furthermore, it may contribute to an improved outcome. In a study using axitinib treatment for Japanese patients with MKC, Tomita et al (11) indicated that baseline proteinuria and soluble VEGFR-2 levels may be predictive factors of axitinib-induced proteinuria, which may also be a predictive factor of a good response to axitinib. With regard to HT, a study of the VEGFR-TKI, cediranib, for non-small cell lung cancer indicated that predictors of VEGFR-TKI-induced HT were as follows: Eastern Cooperative Oncology Group performance status 0; female; normal lactate dehydrogenase levels; and no prior peripheral vascular disease (12). A meta-analysis of sunitinib indicated a significantly higher incidence of sunitinib-induced HT in MKC compared with gastrointestinal stromal tumors (13). These studies indicated that predictors of VEGFR-TKI-induced HT in patients with MKC should exist, and should be identified for extended VEGFR-TKI use during MKC treatment. In the present study, a high baseline systolic BP was the only predictive factor of VEGFR-TKI-induced HT. This result is reasonable and indicated that the evaluation of BP at baseline is significant for managing VEGFR-TKI administration. As controversy remains regarding the optimal treatment for VEGFR-TKI-induced HT, the category of AHTA that is preferable for treatment of secondary HT, based on the charts of 13 de novo HT cases, was investigated. As expected, two major categories of AHTA were used as first-line treatments for VEGFR-TKI-induced HT, CCB and ARB, and there was no difference in efficacy identified between these two AHTA categories. Although certain review studies proposed 
the use of AHTA for VEGFR-TKI-induced HT, there is no evidence that the specific usage of AHTA is a requirement for VEGFR-TKI-induced HT (14-16). However, the unique situation of VEGFR-TKI-induced HT should be considered. It has been reported that ARB may have antitumor effects due to the inhibition of angiotensin II signaling (17). A systematic review indicated that ARB improved progression-free survival in patients with MKC, and that ARB administration was protective against prostate-specific antigen failure in patients with prostate cancer (18). In addition, ARB decreased pressure in the glomerulus, and reduced proteinuria, which consequently inhibited the deterioration of renal function $(19,20)$. As proteinuria is a critical AE of VEGFR-TKI and HT $(7,11)$, ARB may be preferable for patients that are treated with VEGFR-TKI. By contrast, ARB cannot be used for patients with bilateral renal artery stenosis or solitary kidney associated with renal artery stenosis, or for patients with an elevated creatinine level $(>2.0 \mathrm{mg} / \mathrm{dl})$, therefore, $\mathrm{CCB}$ may be appropriate in such cases. Although this was a retrospective study with a small sample size, it was shown that baseline BP may predict VEGFR-TKI-induced HT. Furthermore, no difference in efficacy was identified between CCB and ARB for VEGFR-TKI-induced HT. These findings may aid clinicians with predicting the onset of VEGFR-TKI-induced HT and for its management via the primary use of CCB or ARB.

\section{References}

1. No authors listed: Interferon-alpha and survival in metastatic renal carcinoma: early results of a randomised controlled trial. Medical Research Council Renal Cancer Collaborators. Lancet 353:14-17, 1999.

2. Yang JC, Sherry RM, Steinberg SM, Topalian SL, Schwartzentruber DJ, Hwu P, et al: Randomized study of high-dose and low-dose interleukin-2 in patients with metastatic renal cancer. J Clin Oncol 21: 3127-3132, 2003.

3. McDermott DF, Regan MM, Clark JI, Flaherty LE, Weiss GR, Logan TF, et al: Randomized phase III trial of high-dose interleukin-2 versus subcutaneous interleukin-2 and interferon in patients with metastatic renal cell carcinoma. J Clin Oncol 23: 133-141, 2005.

4. Rini BI, Halabi S, Rosenberg JE, Stadler WM, Vaena DA, Archer L, et al: Phase III trial of bevacizumab plus interferon alfa versus interferon alfa monotherapy in patients with metastatic renal cell carcinoma: final results of CALGB 90206. J Clin Oncol 28: 2137-2143, 2010.

5. Escudier B, Eisen T, Stadler WM, Szczylik C, Oudard S, Staehler M, et al: Sorafenib for treatment of renal cell carcinoma: Final efficacy and safety results of the phase III treatment approaches in renal cancer global evaluation trial. J Clin Oncol 27: 3312-3318, 2009.

6. Motzer RJ,Hutson TE,Tomczak P,Michaelson MD,Bukowski RM, Oudard S, et al: Overall survival and updated results for sunitinib compared with interferon alfa in patients with metastatic renal cell carcinoma. J Clin Oncol 27: 3584-3590, 2009.
7. Rini BI, Escudier B, Tomczak P, Kaprin A, Szczylik C, Hutson TE, et al: Comparative effectiveness of axitinib versus sorafenib in advanced renal cell carcinoma (AXIS): a randomised phase 3 trial. Lancet 378: 1931-1939, 2011.

8. Sternberg CN, Davis ID, Mardiak J, Szczylik C, Lee E, Wagstaff J, et al: Pazopanib in locally advanced or metastatic renal cell carcinoma: results of a randomized phase III trial. J Clin Oncol 28: 1061-1068, 2010.

9. Horsley L, Marti K and Jayson GC: Is the toxicity of anti-angiogenic drugs predictive of outcome? A review of hypertension and proteinuria as biomarkers of response to anti-angiogenic therapy. Expert Opin Drug Metab Toxicol 8: 283-293, 2012.

10. National Cancer Institute: Common Terminology Criteria for Adverse Events v.3.0 and v.4.0 (CTCAE). http://ctep.cancer.gov/ protocolDevelopment/adverse_effects.htm. Accessed March 14, 2014.

11. Tomita Y, Uemura H, Fujimoto H, Kanayama HO, Shinohara N, Nakazawa H, et al; Japan Axitinib Phase II Study Group: Key predictive factors of axitinib (AG-013736)-induced proteinuria and efficacy: a phase II study in Japanese patients with cytokine-refractory metastatic renal cell Carcinoma. Eur J Cancer 47: 2592-2602, 2011.

12. Goodwin R, Ding K, Seymour L, LeMaître A, Arnold A, Shepherd FA, et al; NCIC Clinical Trials Group: Treatment-emergent hypertension and outcomes in patients with advanced non-small-cell lung cancer receiving chemotherapy with or without the vascular endothelial growth factor receptor inhibitor cediranib: NCIC Clinical Trials Group Study BR24. Ann Oncol 21: 2220-2226, 2010.

13. Zhu X, Stergiopoulos K and Wu S: Risk of hypertension and renal dysfunction with an angiogenesis inhibitor sunitinib: systematic review and meta-analysis. Acta Oncol 48: 9-17, 2009.

14. Larochelle P, Kollmannsberger C, Feldman RD, Schiffrin EL, Poirier L, Patenaude F, et al: Hypertension management in patients with renal cell cancer treated with anti-angiogenic agents. Curr Oncol 19: 202-208, 2012.

15. Maitland ML, Bakris GL, Black HR, Chen HX, Durand JB, Elliott WJ, et al; Cardiovascular Toxicities Panel, Convened by the Angiogenesis Task Force of the National Cancer Institute Investigational Drug Steering Committee: Initial assessment, surveillance, and management of blood pressure in patients receiving vascular endothelial growth factor signaling pathway inhibitors. J Natl Cancer Inst 102: 596-604, 2010.

16. Izzedine H, Ederhy S, Goldwasser F, Soria JC, Milano G, Cohen A, et al: Management of hypertension in angiogenesis inhibitor-treated patients. Ann Oncol 20: 807-815. 2009.

17. Miyajima A, Kikuchi E, Kosaka T and Oya M: Angiotensin II type 1 receptor antagonist as an angiogenic inhibitor in urogenital cancer. Rev Recent Clin Trials 4: 75-78, 2009.

18. Mc Menamin ÚC, Murray LJ, Cantwell MM and Hughes CM: Angiotensin-converting enzyme inhibitors and angiotensin receptor blockers in cancer progression and survival: a systematic review. Cancer Causes Control 23: 221-230, 2012.

19. Julius S, Kjeldsen SE, Weber M, Brunner HR, Ekman S, Hansson L, et al; VALUE trial group: Outcomes in hypertensive patients at high cardiovascular risk treated with regimens based on valsartan or amlodipine: the VALUE randomised trial. Lancet 363: 2022-2031, 2004.

20. Lindholm LH, Ibsen H, Dahlöf B, Devereux RB, Beevers G, de Faire U, et al; LIFE Study Group: Cardiovascular morbidity and mortality in patients with diabetes in the Losartan Intervention For Endpoint reduction in hypertension study (LIFE): a randomised trial against atenolol. Lancet 359: 1004-1010, 2002. 